\title{
THE CONNECTING QUANTITIES PROCESS TO SOLVE FRACTION MATHEMATICAL PROBLEMS OF MIDDLE SCHOOL STUDENTS Syarifuddin Syarifuddin $^{1 *}$, Purna Bayu Nugroho ${ }^{2}$, Mutmainah Mutmainah ${ }^{3}$, Arnasari Merdekawati Hadi ${ }^{4}$, Sriaryaningsyih Sriaryaningsyih ${ }^{5}$ \\ ${ }^{1 * 3,4,5}$ STKIP Bima, Bima, Indonesia; ${ }^{2}$ Universitas Muhammadiyah Kotabumi, Indonesia. \\ Email: ${ }^{1 *}$ syarifuddin_mat@ stkipbima.ac.id, ${ }^{2}$ purnabayupvz@gmail.com, 33mutmainah_mat@ stkipbima.ac.id, 4arnasari.mh_mat@stkipbima.ac.id, 5riaryaningsyih_mat@stkipbima.ac.id
}

Article History: Received on $25^{\text {th }}$ July 2020, Revised on $6^{\text {th }}$ September 2020, Published on $17^{\text {th }}$ September 2020

\begin{abstract}
Purpose of the study: The concept of student fraction, in general, is to understand a small part of an intact part so that students' understanding of fractions as quantities needs to be considered in the context of quantitative reasoning. This study aimed to explore and describe the reasoning of junior high school students in Bima, Indonesia, in understanding the relationship of quantities as a fraction.
\end{abstract}

Methodology: Research was conducted with qualitative research, which was descriptive exploratory with the stages of giving the Fraction Problem Task (FPT) and task-based interviews. The subjects in this study were 4 students selected from grades 8 and grade 9, who had studied fraction material and were chosen based on the categorization shown by students on the answer sheet.

Main Findings: The results of this study described that there were two forms of student reasoning approaches, namely the variable and the non-variable approach. In the variable approach, students used multilevel variables, namely level one and level two, whereas, in a non-variable approach, students connected quantities directly, without involving variables.

Applications of this study: The process of connecting quantities involved quantitative reasoning with different quantitative operations, such as the quantity combination in the form of multiplication, addition, and concurrent combination of multiplication and addition.

Novelty/Originality of this study: In the process of linking quantities, students were connecting composite units with intact units directly, and students were connecting composite units, continuous units, and then connecting to intact units.

Keywords: Algebraic Reasoning, Fraction, Unit, Quantity, Quantitative Reasoning.

\section{INTRODUCTION}

The concept of fraction introduced in elementary school to secondary level in Indonesia is only around the smallest parts of the intact part, such as decimal form, fraction number, and percent. Therefore, students do not understand the higher fraction if they are related to reasoning or algebra. Research on the relationship between the difficulty in understanding subtraction on the fourth generation of Indonesians and their opportunities to learn fractions as a snapshot from TIMSS (Trends in International Mathematics and Science Study) demonstrated three reasons that caused students conceptual understanding low (Wijaya, 2017). First, the Indonesian curriculum gave minimum emphasis on the basic concept of fractions and introduced fractional operations too early. Second, Indonesian mathematic textbooks provided only one definition of the fraction that was a fraction as a part of a whole. Third, limited use of the fraction model or fractional representation in the class praxis. Wijaya's research put forward minimum coverage of fractional materials in the curriculum, which interfered with students' reasoning process on the fraction. The crucial aspect of this research was students' reasoning towards fractions. To understand student reasoning infraction, students need to be introduced to the fraction in the form of quantities that can develop quantitative reasoning and students' algebraic reasoning with the fraction.

Some research had evaluated the concept of fraction from the student-reasoning point of view (Baek et al., 2017; Boyce \& Norton, 2016, 2017; Hackenberg, 2007, 2013; Hackenberg et al., 2017; Hackenberg \& Lee, 2015; Norton \& Wilkins, 2009, 2010). Hackenberg (2007) studied unit coordination and fraction construction that required three-level unit interiorization. In the next studies, the three-level unit was categorized as Multiplicative Concept (MC). In MC1, students could only partition the whole unit into parts or composite units Hackenberg (2013). In MC2, students could partition the composite unit in MC1 into a smaller composite unit, while MC3 students could view the whole unit as a commutative operation from the composite unit (Hackenberg \& Lee, 2015). In Table 1, it is given the examples of MC1, $\mathrm{MC} 2$, and MC3.

Further, in the research, Hackenberg (2013) and Hackenberg \& Lee (2015) discussed the relationships between student's knowledge of fractions and their equation writing within the framework of algebraic reasoning. Both studies addressed Multiplicative Concept (MC) using the fractional concept of middle school students (grade 7 until grade10). The studies discussed the relationship between the knowledge of fractions and student's algebraic reasoning in the domain of equation writing. Students showed understanding towards fractions as a composite unit but did not do so on equation writing. The follow-up research conducted by Hackenberg et al. (2017) evaluated 22 middle school students' ways of 
thinking towards unknowns, variables, and equations. Twelve out of twenty-two students were categorized as MC2, who were able to determine numbers and length (of the known quantity) as a whole unit or a composite unit (were capable of imagining the partitioned length but did not partition it). The other ten were categorized as MC3, who were capable of considering numbers and size as a composite unit.

Table 1: Examples of the application of MC1, MC2, and MC3.

\begin{tabular}{lll}
\hline $\begin{array}{l}\text { Multiplicative } \\
\text { Concept (MC) }\end{array}$ & Fraction Value \\
\hline MC1 & The width of the shaded area is $\frac{1}{4}$ parts. \\
\hline MC2 & $\begin{array}{l}\text { The width of the red area is } \frac{1}{4} \text { parts of the above } \frac{1}{4} \text { areas }= \\
\frac{1}{4} \times \frac{1}{4}=\frac{1}{16} .\end{array}$ \\
\hline MC3 & $\begin{array}{l}\text { The width of the blue area is } \frac{1}{5} \text {, whereas the width of } 1 \text { part of } \\
\text { the blue one is } \frac{1}{4} \text { of } \frac{1}{5} \text { parts }=\frac{1}{4} \times \frac{1}{5}=\frac{1}{20} .\end{array}$ \\
\hline
\end{tabular}

Multiplicative Concept (MC) is a visual representation of the symbolic representation of fractions or vice versa by students. The visual representation can help students interpret abstract problems in mathematics so that students can solve fraction problems (Abdullah et al., 2017; Fadhilah et al., 2019). In line with this, Atagi et al. (2016) argue that the visual representation of these fractions can have a good influence on determining symbolic representations. However, symbolic and numeric representations to visual representations are rarely done well (Atagi et al., 2016; Lewis, 2016), and students who are less capable in mathematics will be less effective in learning fractions, but it can be improved through remedial reconceptualization (Lewis, 2017).

By referring to these studies and opinions, this research study described the reasoning process of students in visualizing and solving fraction problems in verbal form, then visualizing and solving the fraction problem.

\section{LITERATURE REVIEW}

\section{Fraction: whole unit, continuous unit, and composite unit as quantities}

The discussion about fractions here referred to the definition stated by Confrey (1994) about splitting. In his definition, he believed that splitting existed in the action of one-to-many. Then, Steffe \& Olive (2010) termed the results of the oneto-many fraction as a continuous unit. Furthermore, Steffe and Olive explained that continuous unit could also be partitioned as "many" in "one-to-many," so the result of the partition was deemed a composite unit. Such a splitting scheme could be used to form the part-to-whole fractional scheme.

The fractional scheme illustrated in several reviews (Baek et al., 2017; Boyce \& Norton, 2016, 2017; Hackenberg, 2007, 2013; Hackenberg \& Lee, 2015; Norton \& Wilkins, 2009, 2010; Thompson \& Saldanha, 2003) was described as $\frac{a}{b}$ form and was understood as a part-to-whole connection. For instance, $\frac{3}{7}$ meant "three out of seven"; were three (3) was a part of a seven (7) that was partitioned into seven parts called a proper fractional scheme. Then, Thompson \& Saldanha $\underline{(2003)}$ illustrated an improper fractional scheme, for example, $\frac{7}{3}$, which showed a fractional iteration that exceeded the whole amount. If $\frac{a}{b}$ was declared as a result of an iteration; then, the iteration as a result of partitions could be classified into three forms: first, an iteration that equaled to the whole partition $\left(\frac{a}{b}\right.$, where $\left.a=b\right)$; second, an iteration that was less than the whole partition $\left(\frac{\mathrm{a}}{\mathrm{b}}\right.$, where $\left.\mathrm{a}<b\right)$; and third, an iteration that exceeded the whole partition, where the available composite unit, if combined, would have bigger amount than the whole $\left(\frac{\mathrm{a}}{\mathrm{b}}\right.$, where $\left.\mathrm{a}>b\right)$.

Just like the illustration on the fraction above, this section sees fractions as a composite unit from parts that are partitioned as a whole. The concept of partition that was illustrated in the previous studies (Baek et al., 2017) used the partition "many" in "one-to-many." For example, $\frac{2}{3}$ from $\frac{3}{4}$, where its three fourth part was partitioned into three equal parts. Therefore, this study used a bamboo stem as an illustration of a whole unit that was cut (partitioned) into two parts (continuous units). Then, one part of the continuous unit was cut $\frac{2}{3}$ off (unit composite). Carraher (1996) differentiate 
quantities that could be considered as a one dimension length and the description of an amount as quantities based on certain unit measurements. This showed that the whole part (a whole unit) can be considered as a quantity, then, a continuous unit and a composite unit as parts of the whole unit is considered as other quantities.

\section{Algebraic Reasoning}

In general, learning about algebra was dominated by integers, but the characteristics of algebra infractions were not much different from those of integers (Hackenberg \& Lee, 2015). One way to distinguish them in learning algebra was by enabling the students to understand them (Thompson, 2013) by developing the basic concept of algebra such as unknowns, variables, equivalence, equations, and functional relationships. Smith \& Thompson (2007) offered some solutions for basic algebra problems by engagement in determining variables, writing algebra equations, and stating and solving an equation. The algebraic problem in this research was observing the way students connected units, whether they use arithmetic operations or algebraic symbols (variables). The coordination and conservation of the quantitative unit took account of composite unit coordination (Olive \& C Cağlayan, 2008). Steffe (1992) explained that a situation which would lead to multiplication (unit coordination by multiplication), needed at least two composite units to coordinate in such a way that one of the composite units could be distributed through the element of the other composite units.

Unit coordination could use a variable approach (Ayalon et al., 2016; Caglayan, 2013; Hackenberg et al., 2017) to substitute a composite unit. For instance, a bamboo stem was cut into six parts; one of the parts could be presupposed as $x$ variable. Therefore the bamboo would have a length of $6 x$ (using coordination of addition or multiplication). The other type of unit coordination did not involve variables (Boyce \& Norton, 2016, 2017; Lobato \& Siebert, 2002). In their research, Lobato \& Siebert (2002) described an illustration from one of the participants (named Terry) in coordinating units from the results partitions. Terry made unit " $2.5 \mathrm{~cm}$ in 1 second" and iteration to produce "10 $\mathrm{cm}$ in 4 seconds". Terry understood the multiplication connections from four groups, with each group consisted of $2.5 \mathrm{~cm}$ in 1 second. The students' ability to regard fractions as measured quantities gave early algebraic reasoning (Hackenberg, 2010; Hackenberg \& Lee, 2015; Norton \& Wilkins, 2010; Olive \& Çağlayan, 2008).

\section{Quantitative Reasoning}

Quantitative reasoning was based on E.L. Thorndike's account on quantitative psychological reasoning through his research about algebra (Dwyer et al., 2003). The framework used by E. L. Thorndike was the stimulus-response, which represented the psychological paradigm in his era. He suggested the typology of problems in quantitative reasoning. The first type was problem-solving without using an explicit equations or common formula. The second type was problem-

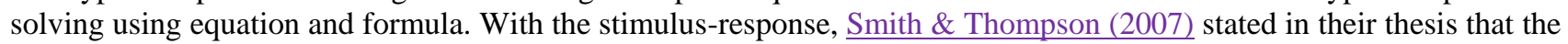
development of quantitative reasoning required years to succeed in improving meaningful and productive arithmetic knowledge and algebra.

Quantitative reasoning focused on quantities and relationships among quantities (Ellis, 2011; Moore, 2014; Stalvey \& Vidakovic, 2015; Syarifuddin et al., 2019a, 2019b, 2020; Thompson, 1993), meaning that approaching the mathematic topic from certain mathematic behavior that emphasized activities, such as measurements, measurement conceptualization, and developing mathematic relationships (Thompson, 1993). The statement was supported by Weber et al. (2014), who stated that quantitative reasoning was the foundation that supported students to model mathematic phenomena by providing the means necessary for students to create connections among quantities in the form of models.

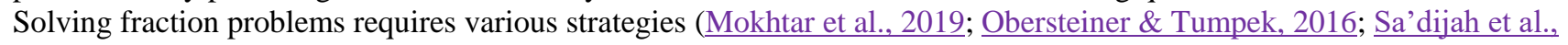
2019; Sa'diyah et al., 2019).

Quantitative reasoning required quantitative mental operation (Thompson, 1995), like in formatting a multiplication comparison of addition comparison and the combination of addition. Quantitative reasoning also required relational reasoning about quantitative structure, mental operational rules to understand situational quantities and mental operational rules, which enabled a person to recognize quantities as something that had various values or could have various values. Thompson (1994) classified quantitative operations into eight types. They were a combination of quantities by addition; comparison of quantities by addition; a combination of quantities by multiplication, comparison of quantities by multiplication; generalizing ratio; instant leveling; making ratio, and making level. The eight types of quantitative operations did not emerge simultaneously. It was dependent on the problems presented or task designs. Therefore the design of the tasks in this research applied only the use of quantitative operation in the form of a combination of quantities by addition and combination of quantities by multiplication.

With the use of the composite unit as a quantity, Caglayan (2013) in his research, showed that identification and coordination of the quantity and unit representations in different categories (multiplication, addition, pseudomultiplication) in which it was an important aspect of quantitative reasoning needing emphasis in the teaching-learning process. Further, the research conducted by Olive \& Cağlayan (2008) showed that the identification and coordination of units involved in the problem situation was an important aspect of quantitative reasoning and needed to be emphasized during the teaching-learning process. 


\section{Research Problem}

This study analyzed students' way of thinking, MC2, and MC3, in solving fractional problems by considering whole unit, continuous unit, and composite unit as quantities in that students connected or coordinated the units which were partitioned from the "part-whole" form. Previous research had examined the formation of equations from fractions, but they did not examine the different ways in which students connected quantities. Therefore, in this study, it was examined how students related quantities to solving fraction problems by looking at whole units, continuous units, and composite units as quantities in terms of quantitative reasoning.

Research problems this could be formulated as follows:

1. How did students connect or coordinate the whole unit, continuous unit, and composite unit as quantities?

2. What reasoning approaches did students use in solving Fraction Problem Task (FPT) with the whole unit, continuous unit, and composite unit as quantities?

\section{METHODOLOGY}

This research was qualitative with the descriptive explorative approach. The characteristic of this qualitative research referred to Creswell (2012), which consisted of a natural setting, researcher as a key instrument, multiple sources of data, inductive data analysis, emergent design, and holistic account.

\section{Participants}

This research was conducted in $8^{\text {th }}$ and $9^{\text {th }}$-grade students of junior high schools in Bima district, Indonesia. The class was chosen after coordinating with the mathematics teacher at the school about the class that had received fraction material in class 7. This was confirmed from the results of Cetin \& Ertekin (2011) research showing that $8^{\text {th }}$ grade high school students had quantitative reasoning abilities. The research subjects were selected from $368^{\text {th }}$ grade students and $319^{\text {th }}$ grade students working on the Fraction Problem Task (FPT) in Figure 1 for 30 minutes. It was obtained that $68^{\text {th }}$ grade students and $59^{\text {th }}$ grade students who gave correct answers and showed different ways of relating the quantities of fractional forms.

The next was to choose a subject whose reasoning was analyzed. In this step, 4 students were selected out of 11 students from the first selection step. The selection procedure was consulting with a math teacher and asking for a recommendation for the students that had oral explanation skill about their work. The 4 selected subjects were two students of 8 Grade and two students of 9 Grade. To differentiate among the 4 students in the results of the research, the students were initialized as S $(\mathrm{S} 1=$ Subject $1, \mathrm{~S} 2=$ Subject 2, S3 = Subject 3, and S4 = Subject 4).

\section{Instrument and Procedures}

Before being used for research, FPT was validated by two mathematicians, namely 1 mathematics teacher and 1 mathematics lecturer. Data were collected using tasks as an instrument, which is available in Figure 1. The task used in this research was Fraction Problem Task (FPT), which was developed to observe the students' reasoning on fractional problems that viewed the whole unit, continuous unit, and composite unit as quantities.

The data collection procedure consisted of several steps. First, students accomplished written FPT in 30 minutes. The results, then, were examined to choose subjects that represented different problem-solving methods. Second, a taskbased clinical interview (Clement, 2000) was conducted for 30 minutes for every student. The interview was done during students' spare time to avoid unnecessary interruption for learning activities. The Interviews were audio and video recorded.

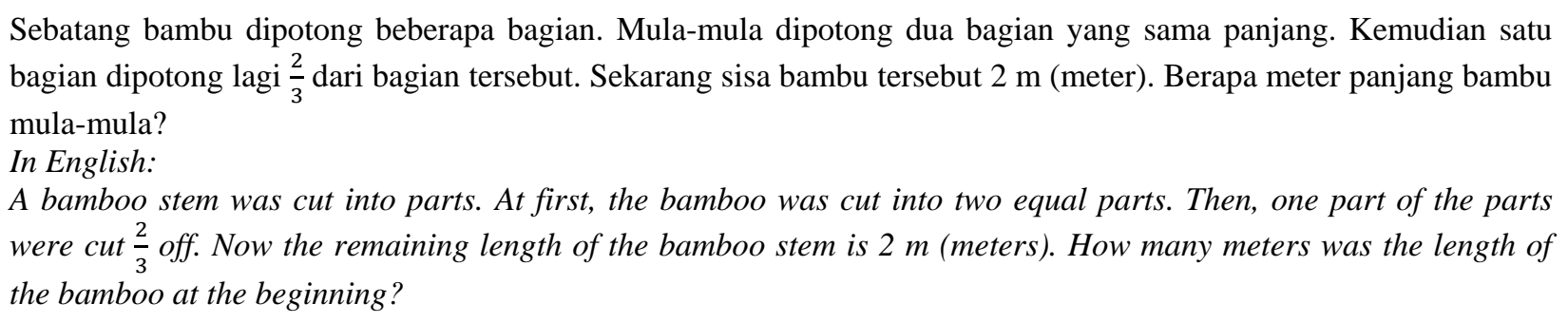

Figure 1: Fraction Problem Task (FPT)

Figure 2 is the flowchart of this research. The beginning stage is a preliminary research plan that consists of studying the problems and the theories under the research, developing an instrument, and designing a research method. At the preparation stage, the researcher determines the location of the study, coordinates with the mathematics teacher, and chooses the research class. The data collection stage begins with giving FPT to students to work on, then evaluates student answer sheets to select the Subjects, and conducts task-based interviews with selected Subjects. Data analysis is 
carried out to process and describe the data obtained, while at the conclusion stage, the researcher is describing the results, findings, and implications of the study. The last stage is the finishing stage, in which the research has been declared as completed by producing a research report.

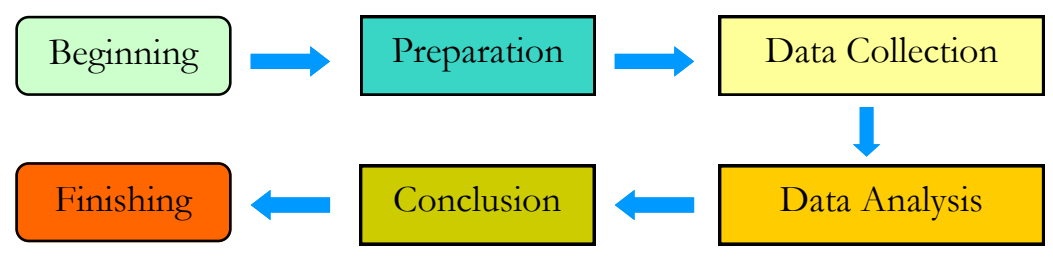

Figure 2: Research Procedure

\section{Data Analysis}

Before conducting in-depth analysis, the data obtained was triangulated by the method (Creswell, 2012), which was to compare the data obtained from the FPT and interviews to find out whether the data from the subject was valid or not. Data analysis involved two stages: first, analyzing students' answer sheets towards FPT by distinguishing representations (Corbin \& Strauss, 2012), namely by differentiating the use of approaches used by students in problem-solving, then differentiating the way students coordinated composite units and continuous units as well as whole units. The second stage, analyzing the results of the interview by playing back recorded video and audio to analyze student reasoning by recording in transcript form. The next was a comprehensive analysis of the work and results of student interviews to identify student reasoning in connecting quantities. A comprehensive analysis was intended to simultaneously analyze student work and interviews.

\section{RESULTS}

This section covers the results of students' work in solving FPT and students' opinions in answering the questions and confirmation from the researcher during the interviews. The results of this research elaborated on the reasoning by all four students that were divided into two groups. The first group was those two students who were engaged in the reasoning using the variable approach. Each was coded as S1 (a Grade 8 student) and S2 (a Grade 9 student). Meanwhile, the second group was the students who were involved in reasoning using a non-variable approach were coded as S3 (a Grade 8 student) and S4 (a Grade 9 student). The elaboration was dominated by the researcher's interpretation of the students' written work. Apart from this, the results of interviews strengthened and confirmed students' reasoning in solving FPT.

\section{Reasoning Using a Variable Approach}

\section{Reasoning Using the First Degree Variable and Using Reasoning Perspective of Coordinating Composite and Whole Units}

To represent the ways of solving FPT, S1 made illustrations as shown in Figure 3. In the illustration, S1 drew what was asked in the tasks and resulted in two figures. The first figure showed a whole bamboo (by writing number 1) and the second figure showed a half chopped bamboo by writing number 1/2).

The reasoning demonstrated by S1 in solving FPT was coordinating a composite unit and a whole unit. This was confirmed by the results of the interviews. The results of the interviews can be seen in the transcript below.

Interview transcript with Subject S1:

Interviewer: How did you do the task?

$\mathrm{S} 1:$ Hmm... I followed the instruction in the task. The bamboo was cut into two equal sizes [showing the figure he drew. See Figure 3], then, tw0-third was cut off half of the bamboo, so the rest was one-third of that part.

Interviewer : Where does one-sixth of this part come from?

$\mathrm{S} 1 \quad$ :Ooh... this one sixth is a part of the whole one bamboo.

Interviewer : Didn't you say that part of the bamboo was one-third of the part?

S1 : Oh yeah, one third of the part equals to this one sixth.

Interviewer : What do you mean?

S1 : This one-third is the rest of half of the whole bamboo after cutting off two-third of that half [pointing at the illustration of a half bamboo which he drew]. And this one-sixth is the rest of one bamboo [while pointing at one whole bamboo that he drew]. That is why I wrote one-sixth equal to two meters. 
Interviewer : I see this [pointing at a half time one third] multiplication of half and one third equals to one over six parts, what does it mean?

S1

: I multiplied a half and one third to find out the rest of the bamboo when it was seen as a whole. I created the second figure [pointing at one-sixth in the figure below] which was another way to find out the rest of the whole bamboo.

Interviewer : Does it mean that you see the bamboo as a whole has been divided into six parts?

S1

: Yes. Therefore the two-meter part is multiplied by six and this makes twelve for the whole length of the bamboo.

Interviewer : By the way, what does this cross mean? [Pointing at variable $x$ ].

S1

: This is $x$ variable. I presuppose one bamboo as $x$.

Within the process of solving the problem, S1 used a variable approach in which $x$ variable is considered as the length of bamboo (a whole unit). Based on his explanation, S1 applies his logic by the quantitative method to coordinate composite and whole units. After finding out the rest, S1 did not coordinate it with the continuous unit but did it directly with the whole unit. The reasoning method applied is the quantitative operation that combines quantity in the form of multiplication where a whole unit is derived from the result of the multiplication of the composite unit.

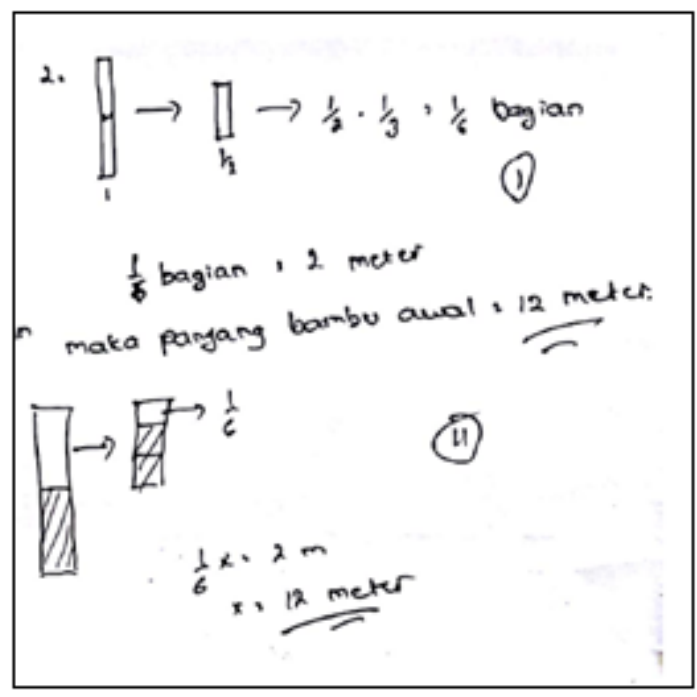

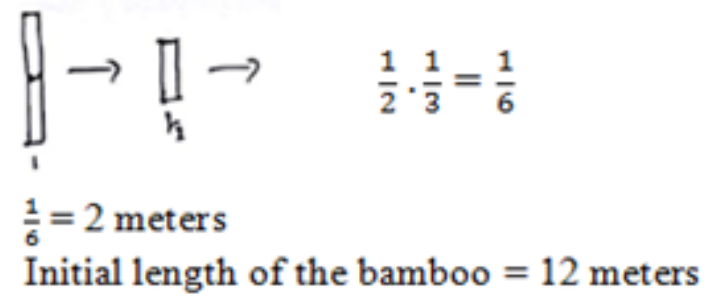

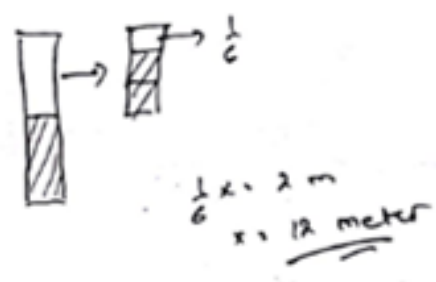

Figure 3: The Representation of S1 in solving FPT

\section{Reasoning Using the Second Level Variable and Using Reasoning Perspective of Coordinating Composite and Continuous Units}

The solutions of FPT done by S2 was in the form of a number line representing the problems (see figure 4). The figure was intended to show an even interval between each part of the composite unit.

Interview transcript with Subject S2:

Interviewer : How did you do the task?

S2 : Firstly, I drew a line to represent a bamboo. I presupposed this bamboo [pointing at the line she drew. See figure 4] as $x$. Afterward, the bamboo was cut into two parts, so I wrote half of $x$ and a half of $x$. Secondly, I spared a half $x$ [pointing at 1/2 which she circled] and considered this half $x$ as the length of a new whole bamboo, so I wrote a half x equals to a. Two third of a was cut [pointing at 2/3a], then, a has one-third remaining part. It is one-third of a known as 2-meter partition.

Interviewer : And...?

S2 : Since there are three parts [pointing at 1/3a, 1/3a, 1/3a], I multiplied two meters and three. Therefore, the length of a half bamboo or a half $x$ equaled to six. The length of one bamboo was made by multiplying six and two which made twelve meters. 
S2 comprehended about variable well. In her explanation, S2 considered a whole unit as $x$ variable. Then, the continuous unit as a result of cutting the bamboo was labeled as a new variable namely $a$, therefore, the reasoning method demonstrated by $\mathrm{S} 2$ was ordinal variable.
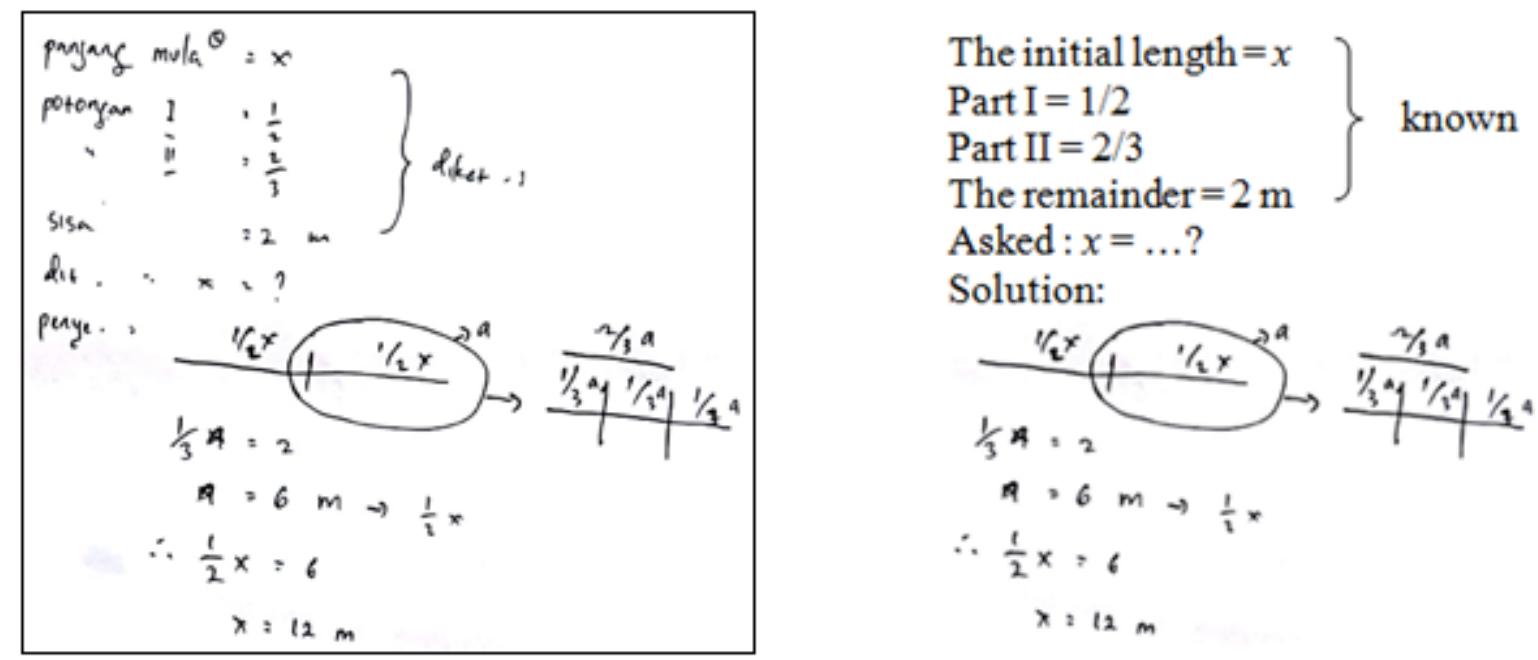

Figure 4: The Representation of S2 in solving FPT

\section{Reasoning Using Non-Variable Approach}

In the case of students' reasoning using a non-variable approach, results were obtained from two students, S3 and S4. Both subjects demonstrated the relatively similar process of reasoning in solving FPT. However, both did not apply the variable approach. S3 did not use illustration to present the problem, while S4 did (see Figure 5 and Figure 6).

Interview Transcript with Subject S3:

Interviewer : How did you solve the problem?

S3 : One bamboo was cut into two parts. Therefore I wrote a half and a half [pointing at 1/2, 1/2]. Then, two-third was cut off the half, so the rest was one third which was two meters.

Interviewer : How did you conclude that the rest was one third? [Pointing at 1/3 in the student's work on FPT].

S3 : Hmmm... I saw a half was cut into three. This two-third was two parts which had equal sizes. Hence, the rest was one part that was one third.

Interviewer : Owh... so? How did you find out that the result was 12 meters?

: One third equals to two meters $(1 / 3=2$ meters $)$. In the meantime, two-third equals to one third added by one third that make two-third; therefore, two-third equals to four meters $(1 / 3+1 / 3=4$ meters $)$. So, the length of a half piece of bamboo is one third added by one third and added again by one third that equals to six meters $(1 / 3+1 / 3+1 / 3=6$ meters). So, the length of the whole bamboo is half of bamboo added by half of bamboo, six meters added by six meters equals to twelve meters.

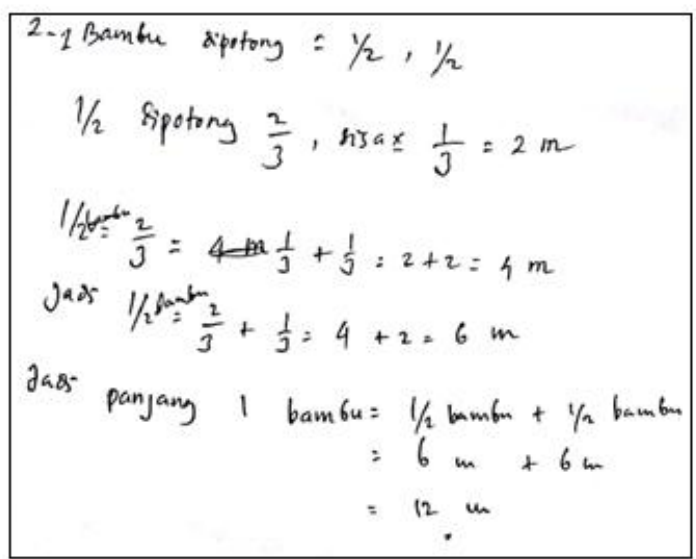

1 bamboo was cut $=1 / 2,1 / 2$

$1 / 2$ is cut $2 / 3$, a remainder of $1 / 3=2 \mathrm{~m}$

$2 / 3=1 / 3+1 / 3=2+2=4 \mathrm{~m}$

So $1 / 2$ bamboo $=2 / 3+1 / 3=4+2=6 \mathrm{~m}$

The length of 1 bamboo $=1 / 2$ bamboo $+1 / 2$ bamboo

$$
\begin{aligned}
& =6 \mathrm{~m}+6 \mathrm{~m} \\
& =12 \mathrm{~m}
\end{aligned}
$$

Figure 5: The Representation of S3 in solving FPT 
Interview transcript with Subject S4:

Interviewer : How did you solve the problem?

S4

: A stem of bamboo is cut into a half and a half. Then, a half piece of bamboo [pointing at 1/2 part in the illustration. See Figure 6] is cut two-third off and the rest is one third which is two meters in length. Since one third means two meters, two-third equals to four meters. Hence, the length of a half of the bamboo is an addition of one third and two-third which make three third [pointing at 3/3] that is two meters added by four meters equals to six meters.

Interviewer : What do you mean by three over three or three third?

S4 : I think that 3/3 comes from a half part which is cut two third off and the rest is one third. So, half of bamboo is made of one third added by two-third.

Interviewer : And what's next?

S4

: The length of a half of bamboo is six meters, so another half of the bamboo has the same length. Therefore, I multiply six and two which makes the length of the bamboo twelve meters.

Based on the results of the representation in solving FPT and interviews with S3 and S4, I could be seen that both subjects comprehended problems of fraction operation well. Both subjects had seen the continuous units as one whole unit as demonstrated in their representation of $1 / 2$ part as $3 / 3$ part.

Both subjects built quantitative reasoning by connecting a composite units and continuous units before doing it to the whole unit. Interestingly, they used different quantitative operations. S3 used quantitative operation by combining quantity using addition while S4 did it by combining quantity using addition and multiplication.

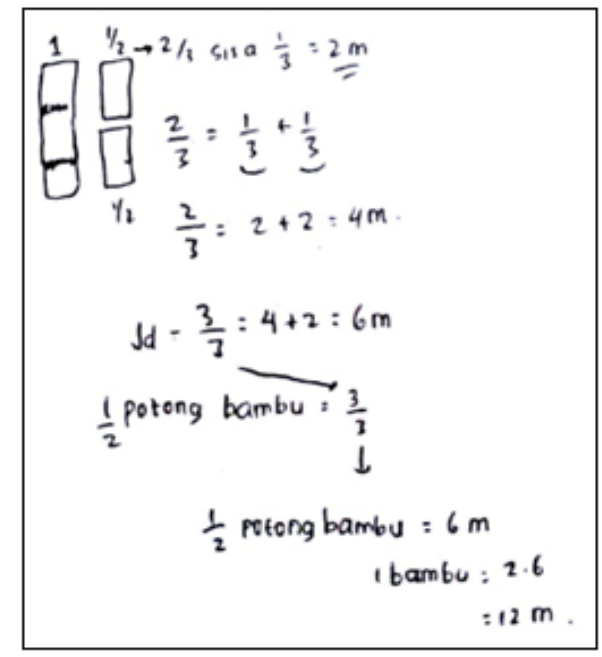

$$
\begin{gathered}
2 / 3 \text { sisanya } 1 / 3=2 \mathrm{~m} \\
2 / 3=1 / 3+1 / 3 \\
2 / 3=2+2=4 \mathrm{~m} \\
\text { So, } 3 / 3=4+2=6 \mathrm{~m} \\
1 / 2 \text { cut bamboo }=3 / 3 \\
1 / 2 \text { cut bamboo }=6 \mathrm{~m} \\
1 \text { bamboo }=2.6 \\
=12 \mathrm{~m}
\end{gathered}
$$

Figure 6: The Representation of S4 in solving FPT

\section{DISCUSSION}

The results of the research revealed the comprehension of high school students' towards partitive and iterative fractional schemes. This was shown by the students' representation in the form of pictures and algebraic symbols. The use and mastery of various forms of representation support students in problem-solving (Mkhatshwa \& Doerr, 2018; Prayitno et al., 2020; Swastika et al., 2020). Students' understanding of the partitive unit could be seen from the way they considered a unit as a variable. There was even a student who illustrated the units with the ordinal variable, as demonstrated in S2's written work. This is due to the ordinal unit partition (Boyce \& Norton, 2016). Further, Steffe \& Olive (2010) stated that a student could make more partitions by seeing a composite unit as a continuous unit, therefore he/she could make a partition to the smaller unit.

In connecting the units above, students built the fractional scheme by doing iterative fractional schemes. Steffe (2001) put forward that the way students thought about fraction (fractional scheme) was derived from the reorganization of psychological operation that they developed when they constructed a scheme to work with the composite units. In the operation of scheme building with the composite unit, students used different approaches such as variable and nonvariable approaches. The use of a variable approach referred to the results of the study by Hackenberg et al. (2017), where high school students used equation (variable) in connecting coordinating units. A non-variable approach is another method for students since it was hard to produce an algebraic equation. It needed guessing and examination of numeric values or indefinite arithmetic operation (Crawford et al., 2019). 
In the application of both approaches, students connect the coordinating unit (whole unit - continuous unit - composite unit) by considering the units as quantities. Therefore, in connecting the quantities, students used quantitative reasoning. The students' quantitative operation was, in this case, the combination of multiplication and addition. This was in line with the results of previous studies as shown in Hackenberg et al. (2017), about the multiplication concept and Steffe (2001) that fractional scheme was built by constructing a series of addition in the whole integers. In their study, Boyce \& Norton (2016) explored the relationship between coordination units using multiplication and addition schemes.

\section{CONCLUSION}

To conclude, there were two approaches that students used to solve FPT, they were variable and non-variable approaches. Students used ordinal variables such as the first and the second level in the variable approach. Students presupposed a whole unit as the first variable (e.g. $x$ variable) and a continuous unit as the second variable (e.g. $a$ variable). It appeared that students' application of the variable approach in FPT would likely develop to the third level on to multilevel variable by presupposing the smallest composite unit as a variable. In the non-variable approach, students connect quantities without using the variable.

In the process of coordinating quantities (e.g. whole units, continuous units, and composite units), it was found that some students connected a composite unit with a whole unit. And some others connect the composite unit with a continuous unit, then, did it to a whole unit. The process of connecting those quantities involved quantitative reasoning. In this particular case, the quantitative operation used by the students wares combination of quantities using multiplication, addition, and the combination of multiplication and addition altogether.

The implication of this research was to increase understanding of the concept of fractions as quantities in secondary school students in developing quantitative and algebraic reasoning. Students not only recognized fractions of their form but also could reason using these fractions. Also, Besides teachers could design learning tasks for middle school students to be able to develop quantitative and algebraic reasoning on the problem of fractions in terms of writing equations and using variables.

\section{LIMITATION AND STUDY FORWARD}

The study of quantitative reasoning on the problem of fractions is not limited to the form as in the task, but it can be designed in the form of tasks using other fraction forms, both fractions in the form of images, in numerical form, and the form of porcelain. The study of quantitative reasoning problems is not limited to the problem of fractions, so it is necessary to study quantitative reasoning by using other problems and on different subjects. Especially for elementary school students, attention needs to be paid to increasing their understanding and quantitative reasoning for learning readiness at a higher level.

\section{ACKNOWLEDGEMENT}

The researchers would like to express their gratitude to the LPDP (Lembaga Pengelola Dana Pendidikan) Indonesia.

\section{AUTHORS CONTRIBUTION}

The first author contributed to the compilation of a research plan, data collection, data transcripts, and data analysis. The second author contributes to providing ideas for research designs, helping to analyze data, and make conclusions. The third author contributes to providing ideas for research, helping to transcribe data, and helping analyze data. The fourth author contributed to providing research ideas, assisting in data collection, and assisting in compiling research reports. The fifth author contributed to providing research ideas, assisting in data collection, and assisting in compiling research reports.

\section{REFERENCES}

1. Abdullah, A. H., Abidin, N. L. Z., \& Mokhtar, M. (2017). Using Thinking Blocks to Encourage the Use of Higher Order Thinking Skills among Students When Solving Problems on Fractions. International Journal of Educational and Pedagogical Sciences.

2. Atagi, N., DeWolf, M., Stigler, J. W., \& Johnson, S. P. (2016). The role of visual representations in college students' understanding of mathematical notation. Journal of Experimental Psychology: Applied. https://doi.org/10.1037/xap0000090

3. Ayalon, M., Watson, A., \& Lerman, S. (2016). Reasoning about variables in 11 to 18 year olds: informal, schooled and formal expression in learning about functions. Mathematics Education Research Journal, 28(3), 379-404. https://doi.org/10.1007/s13394-016-0171-5

4. Baek, J. M., Wickstrom, M. H., Tobias, J. M., Miller, A. L., Safak, E., Wessman-Enzinger, N., \& Kirwan, J. V. (2017). Preservice teachers' pictorial strategies for a multistep multiplicative fraction problem. Journal of Mathematical Behavior, 45, 1-14. https://doi.org/10.1016/j.jmathb.2016.10.005

5. Boyce, S., \& Norton, A. (2016). Co-construction of fractions schemes and units coordinating structures. Journal of Mathematical Behavior, 41, 10-25. https://doi.org/10.1016/j.jmathb.2015.11.003

6. Boyce, S., \& Norton, A. (2017). Dylan's units coordinating across contexts. Journal of Mathematical Behavior, 
45, 121-136. https://doi.org/10.1016/j.jmathb.2016.12.009

7. Caglayan, G. (2013). Prospective mathematics teachers' sense making of polynomial multiplication and factorization modeled with algebra tiles. Journal of Mathematics Teacher Education, 16(5), 349-378. https://doi.org/10.1007/s10857-013-9237-4

8. Carraher, D. W. (1996). Learning about fractions. In P. C. B. G. L. P. Steffe, P. Nesher, G. A. Goldin (Ed.), Theories of mathematical learning (pp. 241-266). Mahwah, New Jersey: Lawrence Erlbaum Associates.

9. Cetin, H., \& Ertekin, E. (2011). The Relationship between Eighth Grade Primary School Students' Proportional Reasoning Skills and Success in Solving Equations. International Journal of Instruction, 4(1), 47-62.

10. Clement, J. (2000). Analysis of clinical interviews : Foundations and model viability. In A. E. Kelly \& R. A. Lesh (Ed.), Handbook of research methodologies for science and mathematics education (pp. 547-589). Mahwah, NJ: Lawrence Erlbaum Associates.

11. Confrey, J. (1994). Splitting, similarity, and rate of change: A new approach to multiplication and exponential functions. In G. Harel \& J. Confrey (Ed.), The development of multiplicative reasoning in the learning of mathematics (pp. 293-332). Albany. NY: State University of New York Press.

12. Corbin, J., \& Strauss, A. (2012). Basics of Qualitative Research (3rd ed.): Techniques and Procedures for Developing Grounded Theory. In Basics of Qualitative Research (3rd ed.): Techniques and Procedures for Developing Grounded Theory. London: Sage Publications. https://doi.org/10.4135/9781452230153

13. Crawford, L., Quebec Fuentes, S., Huscroft-D’Angelo, J., \& Higgins, K. N. (2019). Evaluating Quantitative Reasoning Strategies for Comparing Fractions: A Tool for Teachers. Intervention in School and Clinic. https://doi.org/10.1177/1053451218782443

14. Creswell, J. W. (2012). Educational research: Planning, conducting, and evaluating quantitative and qualitative research. In Educational Research. Thousand Oaks, CA: Sage. https://doi.org/10.1017/CBO9781107415324.004

15. Dwyer, C. A., Gallagher, A., Levin, J., \& Morley, M. E. (2003). What is Quantitative Reasoning? Defining the Construct for Assessment Purposes. ETS Research Report Series. https://doi.org/10.1002/j.23338504.2003.tb01922.x

16. Ellis, A. B. (2011). Algebra in the Middle School: Developing Functional Relationships Through Quantitative Reasoning. In Cai Jinfa \& E. and Knuth (Ed.), Early Algebraization: A Global Dialogue from Multiple Perspectives (pp. 215-238). Berlin, Heidelberg: Springer Berlin Heidelberg. https://doi.org/10.1007/978-3-64217735-4_13

17. Fadhilah, N., Budiarto, M. T., \& Rahaju, E. B. (2019). Mathematical Representation of Middle School Students in Solving Fractional Problems Based on Sex Difference. Journal of Physics: Conference Series. https://doi.org/10.1088/1742-6596/1417/1/012048

18. Hackenberg, A. J. (2007). Units coordination and the construction of improper fractions: A revision of the splitting hypothesis. Journal of Mathematical Behavior, 28(4), 383-432. https://doi.org/10.1016/j.jmathb.2007.03.002

19. Hackenberg, A. J. (2010). Students' reasoning with reversible multiplicative relationships. Cognition and Instruction. https://doi.org/10.1080/07370008.2010.511565

20. Hackenberg, A. J. (2013). The fractional knowledge and algebraic reasoning of students with the first multiplicative concept. Journal of Mathematical Behavior, 32(3), 538-563. https://doi.org/10.1016/j.jmathb.2013.06.007

21. Hackenberg, A. J., Jones, R., Eker, A., \& Creager, M. (2017). “Approximate” multiplicative relationships between quantitative unknowns. Journal of Mathematical Behavior, 48, 38-61. https://doi.org/10.1016/j.jmathb.2017.07.002

22. Hackenberg, A. J., \& Lee, M. Y. (2015). Relationships Between Students' Fractional Knowledge and Equation Writing. Journal for Research in Mathematics Education, 46(2), 196-243. https://doi.org/10.5951/jresematheduc.46.2.0196

23. Lewis, K. E. (2016). Beyond Error Patterns: A Sociocultural View of Fraction Comparison Errors in Students with Mathematical Learning Disabilities. Learning Disability Quarterly. https://doi.org/10.1177/0731948716658063

24. Lewis, K. E. (2017). Designing a Bridging Discourse: Re-Mediation of a Mathematical Learning Disability. Journal of the Learning Sciences. https://doi.org/10.1080/10508406.2016.1256810

25. Lobato, J., \& Siebert, D. (2002). Quantitative reasoning in a reconceived view of transfer. Journal of Mathematical Behavior, 21(1), 87-116. https://doi.org/10.1016/S0732-3123(02)00105-0

26. Mkhatshwa, T. P., \& Doerr, H. M. (2018). Undergraduate Students' Quantitative Reasoning in Economic Contexts. Mathematical Thinking and Learning. https://doi.org/10.1080/10986065.2018.1442642

27. Mokhtar, M. A. M., Ayub, A. F. M., Said, R. R., \& Mustakim, S. S. (2019). Analysis of Year Four Pupils' Difficulties in Solving Mathematical Problems Involving Fraction. International Journal of Academic Research in Business and Social Sciences. https://doi.org/10.6007/IJARBSS/v9-i11/6766

28. Moore, K. C. (2014). Quantitative reasoning and the sine function: The case of Zac. Journal for Research in Mathematics Education, 45(1), 102-138. https://doi.org/10.5951/jresematheduc.45.1.0102

29. Norton, A., \& Wilkins, J. L. M. (2009). A quantitative analysis of children's splitting operations and fraction 
schemes. Journal of Mathematical Behavior, 28(2), 150-161. https://doi.org/10.1016/j.jmathb.2009.06.002

30. Norton, A., \& Wilkins, J. L. M. (2010). Students' partitive reasoning. Journal of Mathematical Behavior, 29(4), 181-194. https://doi.org/10.1016/j.jmathb.2010.10.001

31. Obersteiner, A., \& Tumpek, C. (2016). Measuring fraction comparison strategies with eye-tracking. ZDM Mathematics Education. https://doi.org/10.1007/s11858-015-0742-Z

32. Olive, J., \& Çağlayan, G. (2008). Learners' difficulties with quantitative units in algebraic word problems and the teacher's interpretation of those difficulties. International Journal of Science and Mathematics Education, 6(2), 269-292. https://doi.org/10.1007/s10763-007-9107-6

33. Prayitno, L. L., Purwanto, P., Subanji, S., Susiswo, S., \& As'ari, A. R. (2020). Exploring student's representation process in solving ill-structured problems geometry. Participatory Educational Research. https://doi.org/10.17275/per.20.28.7.2

34. Sa'dijah, C., Handayani, U. F., Sisworo, Sudirman, Susiswo, Cahyowati, E. T. D., \& Sa'Diyah, M. (2019). The Profile of Junior High School Students' Mathematical Creative Thinking Skills in Solving Problem through Contextual Teaching. Journal of Physics: Conference Series. https://doi.org/10.1088/1742-6596/1397/1/012081

35. Sa'diyah, M., Sa'dijah, C., Sisworo, \& Handayani, U. F. (2019). How Students Build Their Mathematical Dispositions towards Solving Contextual and Abstract Mathematics Problems. Journal of Physics: Conference Series. https://doi.org/10.1088/1742-6596/1397/1/012090

36. Smith, J., \& Thompson, P. (2007). Quantitative Reasoning and the Development of Algebraic Reasoning. In \& M. L. B. J. J. Kaput, D. W. Carraher (Ed.), Algebra in the early grades (pp. 95-132). New York: Lawrence Erlbaum.

37. Stalvey, H. E., \& Vidakovic, D. (2015). Students' reasoning about relationships between variables in a realworld problem. Journal of Mathematical Behavior, 40, 192-210. https://doi.org/10.1016/i.jmathb.2015.08.002

38. Steffe, L. P. (1992). Schemes of action and operation involving composite units. Learning and Individual Differences, 4(3), 259-309. https://doi.org/10.1016/1041-6080(92)90005-Y

39. Steffe, L. P. (2001). A new hypothesis concerning children's fractional knowledge. Journal of Mathematical Behavior, 20(3), 267-307. https://doi.org/10.1016/S0732-3123(02)00075-5

40. Steffe, L. P., \& Olive, J. (2010). Children's fractional knowledge. USA: Springer Science \& Business Media. https://doi.org/10.1007/978-1-4419-0591-8

41. Swastika, G. T., Nusantara, T., Subanji, \& Irawati, S. (2020). Alteration representation in the process of translation graphic to graphic. Humanities and Social Sciences Reviews, 8(1), 334-343. https://doi.org/10.18510/hssr.2020.8144

42. Syarifuddin, Nusantara, T., Qohar, A., \& Muksar, M. (2019a). Quantitative reasoning process in mathematics problem solving: A case on covariation problems reviewed from Apos theory. Universal Journal of Educational Research, 7(10), 2133-2142. https://doi.org/10.13189/ujer.2019.071011

43. Syarifuddin, Nusantara, T., Qohar, A., \& Muksar, M. (2019b). The Identification Difficulty of Quantitative Reasoning Process toward the Calculus Students' Covariation Problem. Journal of Physics: Conference Series, 1254(1). https://doi.org/10.1088/1742-6596/1254/1/012075

44. Syarifuddin, S., Nusantara, T., Qohar, A., \& Muksar, M. (2020). Students' Thinking Processes Connecting Quantities in Solving Covariation Mathematical Problems in High School Students of Indonesia. Participatory Educational Research, 7(3), 59-78. https://doi.org/10.17275/per.20.35.7.3

45. Thompson, P. W. (1993). Quantitative reasoning, complexity, and additive structures. Educational Studies in Mathematics, 25(3), 165-208. https://doi.org/10.1007/BF01273861

46. Thompson, P. W. (1994). The development of the concept of speed and its relationship to concepts of rate. In The development of multiplicative reasoning in the learning of mathematics (pp. 179-234).

47. Thompson, P. W. (1995). Notation, Convention, and Quantity in Elementary Mathematics. In J. Sowder \& B. Schapelle (Ed.), Providing a Foundation for Teaching Middle School Mathematics. Albany: NY: SUNY Press.

48. Thompson, P. W. (2013). In the absence of meaning.... In K. R. Leatham (Ed.), Vital directions for mathematics education research (pp. 57-93). New York: Springer. https://doi.org/10.1007/978-1-4614-6977$\underline{3} 4$

49. Thompson, P. W., \& Saldanha, L. A. (2003). Fractions and multiplicative reasoning. In Research companion to the Principles and Standards for School Mathematics (pp. 95-113).

50. Weber, E., Ellis, A., Kulow, T., \& Ozgur, Z. (2014). Six Principles for Quantitative Reasoning and Modeling. The Mathematics Teacher, 108(1), 24-30. https://doi.org/10.5951/mathteacher.108.1.0024

51. Wijaya, A. (2017). The relationships between Indonesian fourth graders' difficulties in fractions and the opportunity to learn fractions: A snapshot of TIMSS results. International Journal of Instruction, 10(4), 221236. https://doi.org/10.12973/iji.2017.10413a 